\title{
PENGARUH LINGKUNGAN KERJA DAN KEPUASAN KERJA TERHADAP LOYALITAS KARYAWAN DI INDUSTRI KREATIF
}

\author{
Verontino Fernando Giovanni ${ }^{1}$, Mei $\mathrm{Ie}^{2}$ \\ ${ }^{1}$ Program Studi Manajemen, Fakultas Ekonomi dan Bisnis, Universitas Tarumanagara \\ Email: verontinofg11@gmail.com \\ ${ }^{2}$ Program Studi Manajemen, Fakultas Ekonomi dan Bisnis, Universitas Tarumanagara* \\ Email:meii@fe.untar.ac.id \\ *Penulis Korespondensi
}

Masuk : 02-08-2021, revisi: 15-08-2021, diterima untuk diterbitkan : 30-08-2021

\begin{abstract}
ABSTRAK
Penelitian ini bertujuan untuk mengetahui pengaruh lingkungan kerja dan kepuasan kerja terhadap loyalitas karyawan pada Industri Kreatif di Jakarta. Jumlah sampel yang digunakan dalam penelitian adalah 51 responden. Metode pengambilan sampel menggunakan non-probability sampling dengan teknik purposive. Metode analisis data dalam penelitian ini adalah PLS-Structural Equation Modeling (PLS-SEM). Hasil penelitian menyimpulkan bahwa lingkungan kerja berpengaruh positif terhadap loyalitas karyawan dan kepuasan kerja berpengaruh positif terhadap loyalitas karyawan.
\end{abstract}

Kata Kunci: Lingkungan Kerja, Kepuasan Kerja, Loyalitas Karyawan

\begin{abstract}
This study aims to determine the effect of work environment and job satisfaction on employee loyalty in the Creative Industry in Jakarta. The number of samples used in the study were 51 respondents. The sampling method used nonprobability sampling with purposive technique. The data analysis method in this study is PLS-Structural Equation Modeling (PLS-SEM). The results of the study concluded that the work environment had a positive effect on employee loyalty and job satisfaction had a positive effect on employee loyalty.
\end{abstract}

Keywords: Work Environment, Job Satisfaction, Employee Loyalty

\section{PENDAHULUAN}

Latar Belakang

Loyalitas karyawan dapat diartikan sebagai keterikatan psikologis atau komitmen pada organisasi dan berkembang sebagai hasil dari kepuasan kerja yang meningkat. Kepuasan kerja dihasilkan dari proses evaluasi internal, dan jika tingkat harapan karyawan terpenuhi atau terlampaui, maka kepuasan tumbuh.

Menurut Rajput et al. (2016) loyalitas karyawan adalah kesediaan untuk tetap bersama organisasi. Menurut Yee et al. (2010 dalam Egenius et al., 2020), yang mendefinisikan loyalitas sebagai kesediaan untuk bertahan dalam organisasi, kemauan untuk melakukan pekerjaan ekstra, memiliki perasaan menjadi bagian dari organisasi, dan menjadikan karyawan lebih bertanggung jawab. Loyalitas karyawan umumnya dipandang sebagai atribut positif yang jelas di tingkat individu dan kolektif. Namun, dalam konteks yang menantang atau disfungsional, karyawan yang setia dapat terpecah antara loyalitas organisasi mereka dan tanggapan pribadi mereka terhadap konflik dan/ atau disfungsi sehingga kesejahteraan pribadi mereka terancam (Johnson $e t$ al., 2017). 
Di era modern ini organisasi bisnis menghadapi beberapa tantangan yang disebabkan oleh sifat lingkungan kerja yang dinamis (Raziq \& Maulabakhsh, 2015 dalam Ashraf, 2019)). Menurut penelitian (Suwati dkk., 2016) tujuan utama seseorang bekerja bukan hanya untuk mendapatkan gaji, tetapi untuk mencapai kepuasan diri. Kinerja karyawan dipengaruhi oleh banyak aspek seperti: motivasi, lingkungan kerja dan kepemimpinan di instansi tersebut. Untuk meningkatkan efisiensi, efektivitas, produktivitas dan komitmen kerja karyawan, bisnis harus memenuhi kebutuhan karyawannya dengan menyediakan kondisi kerja yang baik (Khoreva et al., 2017).

Sejumlah studi sebelumnya mengamati bahwa sebagian besar bisnis mengabaikan lingkungan kerja dalam organisasi sehingga berdampak buruk pada kinerja karyawan mereka (Shu \& Augustinus, 2018). Menurut penelitian tersebut, lingkungan kerja terdiri dari keselamatan karyawan, keamanan kerja, hubungan baik dengan rekan kerja, pengakuan atas kinerja yang baik, motivasi untuk berkinerja baik dan partisipasi dalam proses pengambilan keputusan perusahaan. Mereka lebih jauh menjelaskan bahwa setelah karyawan memahami bahwa perusahaan menganggap mereka penting, mereka akan memiliki tingkat komitmen yang tinggi dan rasa kepemilikan untuk organisasi mereka.

Kepuasan kerja merupakan perasaan senang atau tidak senang pekerja dalam memandang dan menjalankan pekerjaanya (Khoerunnisa \& Rahayuningsih, 2019). Pengaruh kepuasan kerja terhadap loyalitas karyawan juga menjadi topik yang menarik dalam beberapa tahun terakhir. Dalam beberapa penelitian terdahulu menekankan bahwa karyawan yang merasa puas cenderung tidak keluar dari organisasi (Amin et al., 2017; Jahanbazi Goujani et al., 2019). Menurut Tomic et al. (2018) kepuasan kerja sebagai komponen penting dari loyalitas mereka. Kepuasan kerja adalah pendorong terpenting dari loyalitas dan produktivitas karyawan (Amin et al., 2017). Adapun penelitian (Ellys \& Ie, 2020) yang menyatakan, jika karyawan merasa bahwa hasil kerja mereka dihargai oleh pimpinan, diberikan fleksibilitas dalam melaksanakan tugas, diberikan motivasi dalam bekerja, serta selalu diberikan arahan dan bimbingan, maka kepuasan kerja karyawan akan tumbuh sehingga meningkatkan komitmen organisasi karyawan pada perusahaan.

Kepuasan kerja menggabungkan perasaan karyawan yang terkait dengan berbagai dimensi pekerjaan baik intrinsik maupun ekstrinsik, yang melibatkan aspek kepuasan tertentu, termasuk pengawasan. Menurut Miao et al., (2020) kepuasan kerja dapat dipengaruhi beberapa faktor, seperti gaya komunikasi supervisor. Oleh karena itu, pengawasan yang kasar, yang didefinisikan sebagai persepsi bawahan tentang sejauh mana supervisor menampilkan perilaku bermusuhan verbal dan nonverbal, tidak termasuk kontak fisik, telah dipelajari sebagai elemen penting yang dapat mempengaruhi sikap karyawan, yang akibatnya mempengaruhi keberlanjutan organisasi. Dalam mencapai tujuan keberlanjutan organisasi, kepuasan kerja karyawan adalah penting, sedangkan pengawasan etis memainkan peran penting dalam memastikan kepuasan kerja. Menurut Luthans (2006 dalam Tonnisen \& Ie, 2020) terdapat lima faktor yang dapat mempengaruhi kepuasan kerja, yaitu: gaji (upah), pekerjaan itu sendiri, promosi, rekan kerja, dan pengawasan (supervisi).

Saat ini industri kreatif terus dihadapkan dengan tingkat kompetisi yang cukup tinggi dan ekspetasi yang cukup besar dari pasar (Ozimek, 2017). Menurut Ricky J. Pesik (Wakil Kepala Badan Ekonomi Kreatif) di Indonesia, industri kreatif merupakan salah satu industri yang paling banyak diprioritaskan untuk menciptakan pertumbuhan ekonomi nasional. Sebagai negara berkembang (Tannady \& Maimury, 2018), Indonesia telah mendapatkan kontribusi pendapatan nasional yang cukup baik dari industri kreatif. Berdasarkan laporan Badan Ekonomi Kreatif (BEKRAF) yang dirilis tahun 2019 menunjukkan pada tahun 2018, industri kreatif di Indonesia 
memberikan kontribusi sebesar 7,44\% terhadap total perekonomian nasional Indonesia. Serta nilai ekspor ekonomi kreatif Indonesia mencapai \$22,07 Miliar US. Industri kreatif juga mampu menyerap tenaga kerja dalam jumlah besar. Di Indonesia, ada sekitar 19 juta orang yang bekerja di sektor industri kreatif. Dengan pesatnya pertumbuhan industri kreatif di Indonesia, hal ini akan menuntut kinerja dan motivasi kerja yang lebih tinggi pada sumber daya manusia guna mempertahankan kinerja dan kualitas industri tersebut (Tannady et al., 2019). Dalam penelitian ini akan melihat populasi berasal dari kalangan profesional sebagai instrumen utama (pemilik ide kreatif) dan yang bekerja di bidang kreatif (periklanan, desain, fashion, film, musik, dan software) (Loy \& Aageson, 2018) di perusahaan yang berfokus di industri kreatif.

Dari rangkaian teori dan uraian yang telah diungkapkan tentang faktor-faktor yang dapat mempengaruhi loyalitas karyawan yaitu lingkungan kerja dan kepuasan kerja dipilih sebagai variabel yang dapat mempengaruhi loyalitas karyawan (variabel eksogen). Tujuan penelitian ini adalah untuk melihat pengaruh langsung ketiga variabel endogen terhadap variable eksogen (loyalitas), pengaruh langsung lingkungan kerja terhadap loyalitas karyawan dan pengaruh langsung variabel kepuasan kerja terhadap loyalitas kerja.

\section{Loyalitas Karyawan}

Menurut Yu et al., (2019) loyalitas adalah karyawan yang memandang secara positif dalam mengidentifikasi nilai-nilai perusahaan dan strategi yang dapat ditelusuri di luar komitmen terhadap sikap, kemudian ditunjukkan dalam loyalitas perilaku. Menurut Johnson et al. (2017) loyalitas karyawan umumnya dipandang sebagai atribut positif yang jelas di tingkat individu dan kolektif. Namun, dalam konteks yang menantang atau disfungsional, karyawan yang setia dapat terpecah antara loyalitas organisasi mereka dan tanggapan pribadi mereka terhadap konflik dan/ atau disfungsi sehingga kesejahteraan pribadi mereka terancam. Menurut Waqas et al. (2014 dalam Dhir et al., 2020) loyalitas karyawan merupakan perilaku kewarganegaraan organisasi yang mencerminkan kesetiaan kepada organisasi untuk mempromosikan kepentingan dan citranya kepada pihak luar.

Dari beberapa definisi di atas mengenai loyalitas karyawan dapat disimpulkan bahwa loyalitas karyawan merupakan kesetiaan karyawan terhadap organisasi atau perusahaan.

\section{Lingkungan Kerja}

Menurut Danish et al. (2013 dalam Jawaad et al., 2019) dimana peneliti mengidentifikasi lingkungan kerja sebagai atmosfer perusahaan dimana karyawan melakukan pekerjaan mereka. Agar berhasil, perusahaan harus merencanakan lingkungan kerja mereka sedemikian rupa sehingga memperluas tingkat dedikasi dan inspirasi karyawan yang pada akhirnya akan menghasilkan hasil yang ideal. Menurut Okasheh \& AL-Omari (2017), lingkungan kerja merupakan segala sesuatu yang berada di sekitar karyawan dan dapat berpengaruh dalam proses kerjanya. Menurut Sunyoto (2012 dalam Ramli, 2019) lingkungan kerja adalah segala sesuatu yang ada di sekitar karyawan dan yang dapat mempengaruhi dirinya dalam melaksanakan tanggung jawab dan tugas yang diberikan kepadanya.

Berdasarkan definisi yang telah dikemukakan diatas terdapat kesamaan dimana lingkungan kerja merupakan segala aspek yang ada di sekitar karyawan baik fisik maupun non-fisik yang dapat mempengaruhi karyawan dalam melaksanakan tugasnya dalam suatu pekerjaan.

\section{Kepuasan Kerja}

Menurut Shah et al. (2017) kepuasan kerja dapat dilihat sebagai motivator kunci (pemain) dari 
perilaku manusia di lingkungan kerja. Menurut Huang \& Hsiao (2007 dalam Panda et al., 2021) kepuasan kerja digambarkan sebagai keadaan emosional yang menyenangkan atau positif yang dihasilkan dari penilaian seseorang atas pekerjaan dan pengalaman kerja seseorang, sedangkan komitmen organisasi dipahami sebagai kekuatan identifikasi individu dengan, dan keterlibatan dalam, organisasi tertentu. Menurut Lee et al. (2016) kepuasan kerja adalah kondisi emosional yang menyenangkan yang disebabkan oleh penilaian pribadi terhadap kondisi kerja dan pengalaman kerja individu dalam organisasi.

Dari beberapa definisi mengenai kepuasan kerja yang terdapat diatas, dapat disimpulkan bahwa kepuasan kerja merupakan keadaan emosional atau perasaan positif dari penilaian seseorang terhadap kondisi kerja dan pengalaman kerja yang mereka rasakan.

Lingkungan kerja memiliki pengaruh positif dan signifikan terhadap loyalitas karyawan. Lingkungan kerja yang baik dapat meningkatkan aktivitas karyawan dalam melakukan tanggung jawab dalam pekerjaannya, dengan kondisi lingkungan kerja yang aman, nyaman serta kondusif diikuti dengan kebutuhan yang terpenuhi bagi karyawan dapat menjadi faktor meningkatnya loyalitas karyawan terhadap organisasi. Begitu juga dengan kepuasan kerja yang memiliki pengaruh positif dan signifikan terhadap loyalitas karyawan, dimana jika karyawan merasa puas akan pekerjaan yang diberikan oleh perusahaan maka loyalitas karyawan dapat meningkat dan akan berdampak terhadap keinginan karyawan untuk bertahan di perusahaan tempat mereka bekerja. Oleh karena itu, dapat disimpulkan model penelitian dengan variabelvariabel berikut ini:

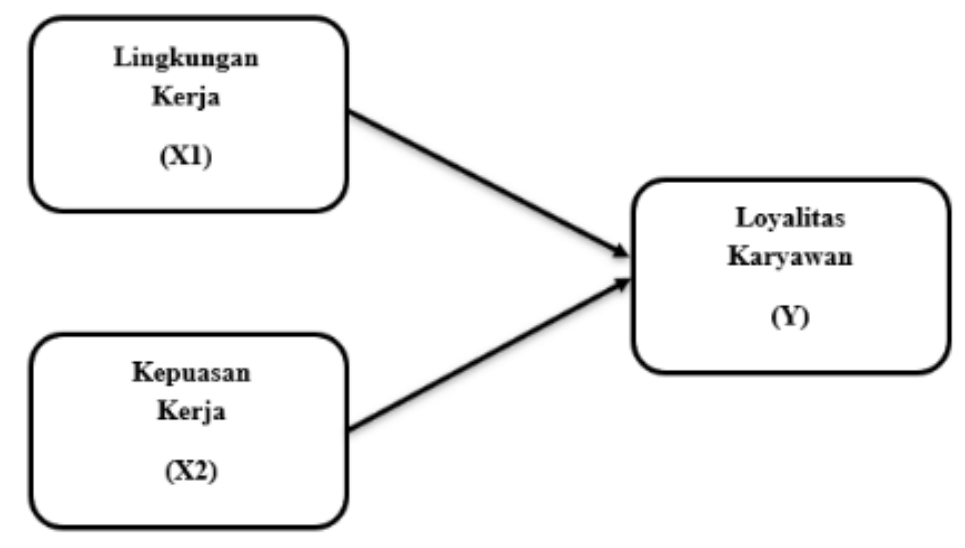

Gambar 1. Model penelitian

Berdasarkan kajian teori dan kerangka pemikiran, maka hipotesis yang digunakan dalam penelitian ini adalah sebagai berikut:

$\mathrm{H}_{1}$ : Lingkungan kerja memiliki pengaruh positif dan signifikan terhadap loyalitas karyawan.

$\mathrm{H}_{2}$ : Kepuasan kerja memiliki pengaruh positif dan signifikan terhadap loyalitas karyawan.

\section{METODE PENELITIAN}

Metode penelitian yang digunakan dalam penelitian ini adalah metode penelitian kuantitatif. Desain penelitian yang digunakan dalam penelitian ini adalah penelitian deskriptif. Pengukuran variabel yang digunakan dalam penelitian ini adalah skala likert.

Populasi pada penelitian ini merupakan karyawan yang berasal dari kalangan profesional di industri kreatif di kota Jakarta dengan jumlah kurang lebih 1 juta orang. Penelitian ini menggunakan purposive sampling. Dalam penelitian ini, jumlah sampel yang diambil adalah 51 
responden yang merupakan karyawan pada industri kreatif di bidang periklanan, desain, fashion, film, musik, dan software di kota Jakarta. Metode pengambilan sampel dilakukan secara online menggunakan kuesioner dalam bentuk google form. Dalam penelitian ini, peneliti menggunakan Partial Least Square yang merupakan salah satu metode analisis data menggunakan Structural Equation Modeling (SEM) atau disebut juga PLS-SEM. Untuk mengolah data-data nya, peneliti menggunakan bantuan software, yaitu dengan software SmartPLS versi 3.3.3.

\section{HASIL DAN PEMBAHASAN}

\section{Uji Validitas}

Untuk mengukur instrumen dalam penelitian ini maka menggunakan dua validitas yaitu: convergent validity dan discriminant validity. Convergent validity dapat diukur dengan melihat dari nilai Average Variance Extracted (AVE) dan loading factor yang ada dalam setiap indikator. Chin \& Newsted (1998 dalam Ghozali, 2016) untuk penelitian tahap awal dari pengembangan skala pengukuran nilai loading 0,5 sampai 0,6 sudah dianggap cukup memadai. Nilai AVE yang diharapkan adalah lebih besar dari 0,5 (Supranto \& Limakrisna, 2019). Hasil uji validitas dapat dilihat pada Gambar 2.

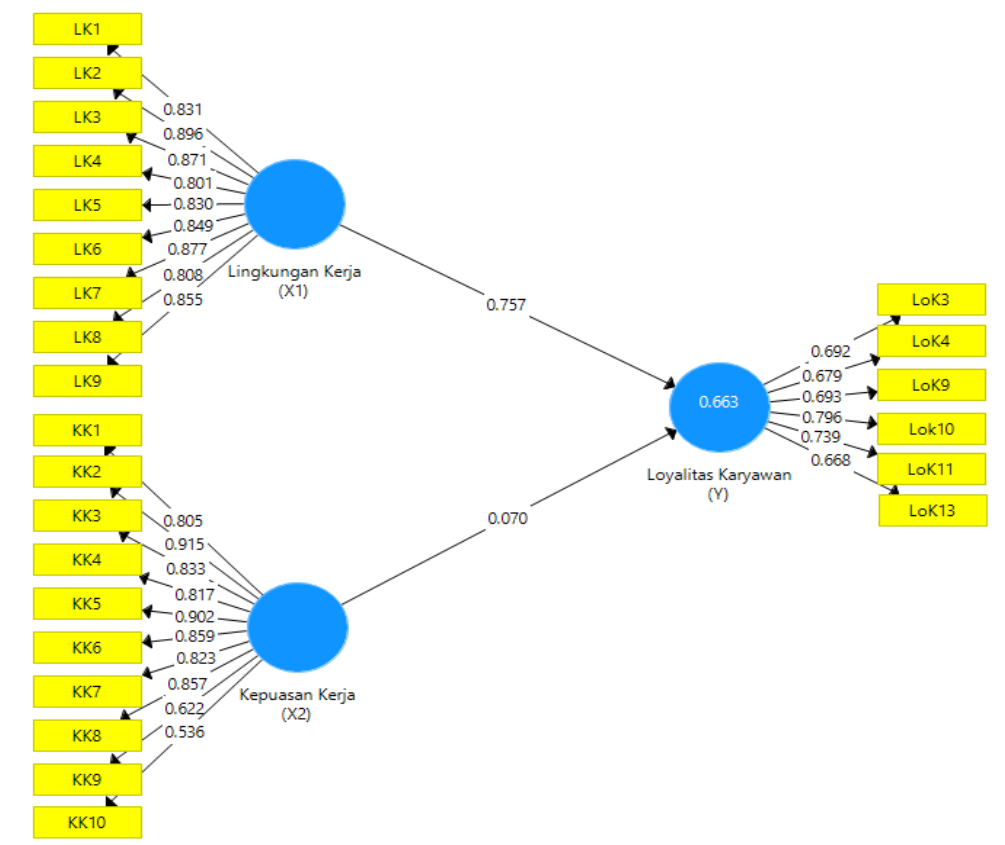

Gambar 2. Hasil Analisis Convergent Validity

Sumber: Hasil Pengolahan Data dengan menggunakan Software SmartPLS Versi 3.3.3

\section{Uji Reliabilitas}

Pengujian reliabilitas dapat dilihat dari hasil nilai cronbach's alpha dan composite reliability. Suatu instrumen dinyatakan reliabel jika nilai dari cronbach's alpha dan composite reliability lebih besar dari 0,6 (Hair et al., 2017). Hasil analisis reliabilitas dapat dilihat pada Tabel 1.

Tabel 1. Hasil analisis reliabilitas

Sumber: Hasil Pengolahan Data dengan menggunakan Software SmartPLS Versi 3.3.3

\begin{tabular}{|c|c|c|}
\hline Variabel & Cronbach's Alpha & Reliabilitas Komposit \\
\hline Lingkungan Kerja $\left(\mathrm{X}_{1}\right)$ & 0.951 & 0.958 \\
\hline Kepuasan Kerja $\left(\mathrm{X}_{2}\right)$ & 0.937 & 0.948 \\
\hline Loyalitas Karyawan $(\mathrm{Y})$ & 0.808 & 0.860 \\
\hline
\end{tabular}




\section{Hasil Uji R ${ }^{2}$}

$\mathrm{R}^{2}$ menunjukkan bahwa adanya efek pengaruh variabel laten eksogen terhadap variabel laten endogen memiliki pengaruh yang substantive. Nilai koefisien determinasi dikategorikan menjadi tiga kategori, yaitu nilai $\mathrm{R}^{2}$ sebesar 0,25 diindikasikan lemah, nilai $\mathrm{R}^{2}$ sebesar 0,50 diindikasikan moderat dan nilai $\mathrm{R}^{2}$ sebesar 0,75 diindikasikan substansial.

Tabel 2. Hasil uji $\mathrm{R}^{2}$

Sumber: Hasil Pengolahan Data menggunakan software SmartPLS Versi 3.3.3

\begin{tabular}{|c|c|c|}
\hline Variabel & R-Square & Adjusted $R-$ Square \\
\hline Loyalitas Karyawan (Y) & $\mathbf{0 , 6 6 3}$ & $\mathbf{0 , 6 4 9}$ \\
\hline
\end{tabular}

Berdasarkan Tabel 2 dijelaskan bahwa hasil analisis $\mathrm{R}^{2}$ dari loyalitas karyawan sebesar 0,663. Artinya 66,3\% variabel loyalitas karyawan dapat dijelaskan oleh lingkungan kerja dan kepuasan kerja serta sisanya 33,7\% dijelaskan oleh variabel lain di luar penelitian ini. Nilai R-Square pada penelitian ini dikategorikan moderat.

\section{Hasil Uji $Q^{2}$}

Pengukuran ini cocok jika variabel laten endogen memiliki model pengukuran reflektif. $Q$ Square $\left(\mathrm{Q}^{2}\right)$ atau dikenal dengan Stone-Geisser's memiliki nilai $\mathrm{Q}^{2}$ yang dihasilkan melalui prosedur blindfolding. Prosedur ini hanya diterapkan pada variabel yang dipengaruhi menggunakan pengukuran reflektif.

Tabel 3. Hasil uji $Q^{2}$

Sumber: Hasil Pengolahan Data menggunakan software SmartPLS Versi 3.3.3

\begin{tabular}{|c|c|c|c|}
\hline Variabel & SSO & SSE & $\mathrm{Q}^{2}(=1-\mathrm{SSE} / \mathrm{SSO})$ \\
\hline Lingkungan Kerja $\left(\mathrm{X}_{1}\right)$ & 459.000 & 459.000 & \\
\hline Kepuasan Kerja $\left(\mathrm{X}_{2}\right)$ & 510.000 & 510.000 & \\
\hline Loyalitas Karyawan $(\mathrm{Y})$ & 306.000 & 219.119 & 0.284 \\
\hline
\end{tabular}

Berdasarkan Tabel 3 dijelaskan bahwa hasil analisis $\mathrm{Q}^{2}$ menunjukkan bahwa nilai $\mathrm{Q}^{2}$ lebih besar dari 0 (nol) menunjukkan nilai-nilai yang diobservasi sudah direkontsruksi dengan baik. Sehingga dapat disimpulkan bahwa semua variabel memiliki relevansi prediktif.

\section{Hasil Uji $f^{2}$}

Uji ini dilaksanakan untuk mengetahui bagaimana variabel prediktor memiliki efek dalam model struktural. Menurut Hair et al. (2017) jika nilai $f^{2}$ sebesar 0,02 memiliki pengaruh yang lemah, jika nilainya sebesar 0,15 maka memiliki pengaruh sedang, jika nilainya sebesar 0,35 maka memiliki pengaruh yang kuat pada level struktural.

Tabel 4. Hasil Uji $f^{2}$

Sumber: Hasil Pengolahan Data menggunakan software SmartPLS Versi 3.3.3

\begin{tabular}{|c|c|}
\hline Variabel & $\boldsymbol{f}^{\mathbf{2}}$ \\
\hline Lingkungan Kerja $\rightarrow$ Loyalitas Karyawan & 0,568 \\
\hline Kepuasan Kerja $\rightarrow$ Loyalitas Karyawan & 0,005 \\
\hline
\end{tabular}

Dalam Tabel 4 diketahui jika nilai effect size dalam variabel lingkungan kerja terhadap loyalitas karyawan sebesar 0,568, variabel kepuasan kerja terhadap komitmen organisasi sebesar 0,005. Setiap hasil mempunyai efek masing-masing. Hasil 0,005 memiliki pengaruh yang lemah, dan hasil 0,568 memiliki pengaruh yang kuat. 


\section{Hasil Uji Goodness of Fit}

Nilai GoF didapat dari akar kuadrat Average Variance Extracted dikali dengan nilai rata-rata $\left(\mathrm{R}^{2}\right)$. Jika nilai GoF 0,1 maka interpretasi dari nilai GoF kecil, bila nilai GoF 0,25 maka merupakan interpretasi nilai GoF yang menengah, dan nilai GoF 0,36 yang merupakan interpretasi nilai GoF yang besar.

Perhitungan pengujian Goodness of Fit dilakukan secara manual yang melibatkan nilai Average Variance Extracted (AVE) dan $\mathrm{R}^{2}$. Berikut disajikan perhitungan Goodness of Fit (GoF) adalah sebagai berikut:

$$
\begin{aligned}
& \mathrm{AVE}=(0,718+0,649+0,508) / 3=0,625 \\
& \text { GoF }=\sqrt{A V E \times R^{2}} \\
& \text { GoF }=\sqrt{0,625 \times 0,663} \\
& \text { GoF }=0,644
\end{aligned}
$$

\section{Hasil Uji Hipotesis}

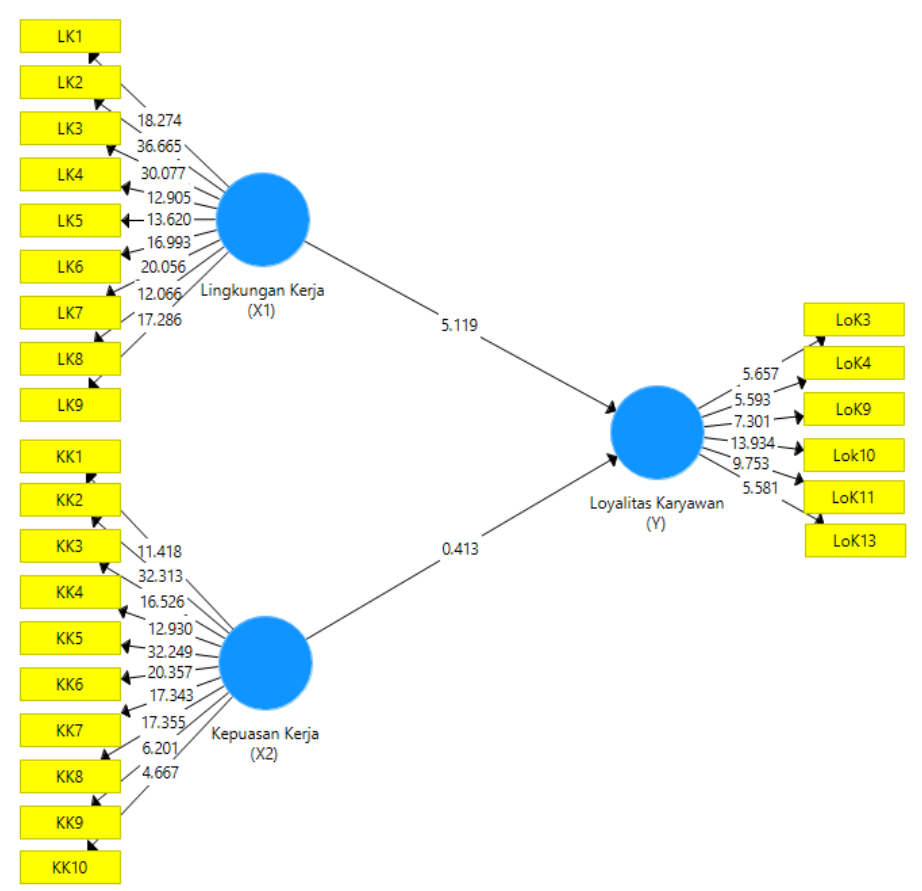

Gambar 3. Hasil pengujian bootstrapping

Sumber: Hasil Pengolahan Data menggunakan software SmartPLS Versi 3.3.3

Tabel 5. Hasil uji hipotesis

Sumber: Hasil Pengolahan Data menggunakan software SmartPLS Versi 3.3.3

\begin{tabular}{|c|c|c|}
\hline Variabel & t-statistik & p-values \\
\hline Lingkungan Kerja $\rightarrow$ Loyalitas Karyawan & 5,119 & 0,000 \\
\hline Kepuasan Kerja $\rightarrow$ Loyalitas Karyawan & 0,413 & 0,680 \\
\hline
\end{tabular}

Berdasarkan Tabel 5, dapat dilihat jika variabel lingkungan kerja memiliki $t$-statistics sebesar 5.119 dan $p$-values sebesar 0,000. Dapat diartikan $t$-statistics yang melebihi 1,96 dan $p$ values kurang dari 5\% atau 0.05, maka dalam hipotesis 1 diterima. Dengan demikian, lingkungan kerja berpengaruh positif dan signifikan terhadap loyalitas karyawan. Berdasarkan Tabel 5, dapat dilihat jika variabel lingkungan kerja memiliki t-statistics sebesar 0,413 dan p-values sebesar 0,680. Dapat diartikan $t$-statistics yang kurang dari 1,96 dan $p$ values lebih dari $5 \%$ atau 
0.05, maka dalam hipotesis 2 ditolak. Dengan demikian, kepuasan kerja berpengaruh positif dan tidak signifikan terhadap loyalitas karyawan.

\section{Diskusi}

\section{Pengaruh Lingkungan Kerja terhadap Loyalitas Karyawan}

Berdasarkan hasil penelitian, lingkungan kerja memiliki pengaruh yang positif dan signifikan terhadap komitmen organisasi, dengan nilai sampel asli sebesar 0,777, nilai t-statistik sebesar 5,119 , dan nilai p-values sebesar 0,000. Ini disebabkan karena perusahaan sudah mengupayakan lingkungan kerja yang dapat mendukung kenyamanan karyawannya dalam bekerja sehingga dapat meningkatkan loyalitas karyawan di dalam perusahaan. Hasil penelitian ini didukung oleh Rohimah (2018) yang menyatakan bahwa lingkungan kerja memiliki pengaruh positif dan signifikan terhadap loyalitas karyawan. Artinya, semakin baik lingkungan kerja pada perusahaan, maka tingkat loyalitas karyawan terhadap perusahaan akan semakin tinggi. Hal ini sejalan dengan penelitian Alyani \& Djastuti (2017) yang menyatakan lingkungan kerja berpengaruh positif dan signifikan terhadap loyalitas karyawan. Artinya, semakin aman dan nyaman lingkungan kerja maka karyawan dapat bekerja secara optimal. Dan semakin kondusif lingkungan kerja maka akan semakin besar juga kemungkinan karyawan setia terhadap perusahaan.

Jika karyawan merasa tempat mereka bekerja memiliki bangunan yang menarik, peralatan kerja yang disediakan perusahaan memadai, merasa nyaman dengan fasilitas untuk tempat beristirahat, mendapatkan fasilitas tempat beribadah yang baik, dan tersedianya angkutan umum bagi karyawan di sekitar tempat mereka bekerja, maka karyawan cenderung akan memiliki loyalitas karyawan yang tinggi terhadap perusahaan. Dengan adanya kerjasama yang baik dalam bekerja dan kekeluargaan yang tinggi dalam hubungan kerja maka karyawan akan merasa nyaman untuk bekerja dalam suatu perusahaan yang mengakibatkan semakin tingginya loyalitas mereka terhadap perusahaan. Rasa menghargai dan hubungan baik dari atasan terhadap karyawan juga merupakan faktor penting yang dapat mendorong loyalitas karyawan terhadap perusahaan, dengan tingginya tingkat rasa menghargai dari atasan dan hubungan yang baik dari atasan kepada karyawan akan memicu bertambahnya loyalitas karyawan terhadap perusahaan.

\section{Pengaruh Kepuasan Kerja terhadap Loyalitas Karyawan}

Berdasarkan hasil penelitian, kepuasan kerja memiliki pengaruh yang positif dan tidak signifikan terhadap loyalitas karyawan, dengan nilai sampel asli sebesar 0,070, nilai t-statistik sebesar 0,413 , dan nilai $p$ values sebesar 0,680. Ini disebabkan karena karyawan belum merasa puas dalam bekerja, sehingga loyalitas karyawan terhadap perusahaannya belum tercipta. Hasil penelitian ini tidak sejalan dengan hasil penelitian Jun et al. (2006 dalam Dhir et al., 2020) yang menyatakan bahwa kepuasan kerja memiliki pengaruh positif dan signifikan terhadap loyalitas karyawan. Artinya semakin baik kepuasan kerja karyawan, belum tentu memperbesar tingkat loyalitas karyawan terhadap perusahaan. Hal ini juga tidak sesuai dengan penelitian Egenius et al. (2020) yang menyatakan kepuasan kerja memiliki pengaruh positif dan signifikan terhadap loyalitas karyawan. Artinya, semakin tinggi kepuasan kerja yang dirasakan oleh karyawan namun peningkatannya hanya sedikit.

Hal ini membuktikan bahwa di dalam perusahaan tersebut tidak ada bukti bahwa karyawan yang merasa puas dengan pekerjaannya, merasa pekerjaan yang mereka kerjakan menantang, merasa gaji yang mereka terima telah sesuai dengan hasil kerja mereka, merasa puas dengan gaji yang diterima, memiliki kesempatan untuk memperoleh promosi jabatan, merasa senang dengan peraturan akan promosi jabatan, merasa puas dengan pengawasan, memiliki rekan kerja yang 
dapat memberikan semangat dan dukungan dalam bekerja dan memiliki hubungan yang baik dengan rekan kerjanya, menjamin keberadaan mereka untuk menetap di perusahaan. Jika mereka mendapat penawaran yang lebih baik, tidak menutup kemungkinan bahwa mereka akan pindah, terlebih lagi apabila di perusahaan lain mereka menemukan bahwa rekan kerjanya dapat memberikan semangat dan dukungan yang lebih serta dapat berhubungan baik antar rekan kerja.

\section{KESIMPULAN DAN SARAN}

Dalam suatu penelitian pasti terdapat suatu keterbatasan. Pada penelitian ini, terdiri dari beberapa keterbatasan, yaitu peneliti hanya menggunakan beberapa variabel seperti, lingkungan kerja, kepuasan kerja dan loyalitas karyawan. Penelitian ini belum mendapatkan hasil yang maksimal dikarenakan oleh penyebaran hanya dilakukan melalui media sosial, juga karena keterbatasan waktu dan kondisi di masa pandemi COVID-19.

Berdasarkan hasil penelitian, menunjukkan bahwa lingkungan kerja berpengaruh positif dan signifikan terhadap loyalitas karyawan di industri kreatif di Jakarta, dan kepuasan kerja bepengaruh positif dan tidak signifikan terhadap loyalitas karyawan di industri kreatif di Jakarta, maka peneliti akan memberikan saran yang bermanfaat bagi perusahaan. Pertama, perusahaan perlu lebih memperhatikan pemberian semangat dan dukungan antar pekerja sehingga dapat menciptakan kepuasan kerja yang lebih bagi setiap karyawannya. Dengan adanya pemberian semangat dan dukungan antar pekerja maka setiap karyawan yang bekerja di perusahaan akan merasa lebih puas dan dapat memberikan pekerjaan terbaiknya. Misalnya dengan memberikan tantangan untuk bekerja sebagai sebuah tim dan dengan imbalan pemberian bonus kepada tiap-tiap anggota, maka dengan tindakan seperti itu pemberian semangat dan dukungan antar pekerja dapat meningkat. Kedua, perusahaan diharapkan dapat membantu setiap karyawannya untuk membangun hubungan yang baik antar rekan kerja sehingga mereka dapat lebih nyaman untuk bekerja bersama. Misalnya dengan mengadakan acara buka bersama secara daring agar mereka dapat menjalin hubungan yang lebih baik diluar dari pekerjaan mereka. Ketiga, perusahaan perlu lebih memperhatikan hasil pekerjaan setiap karyawan disaat tidak adanya pengawasan untuk memastikan bahwa karyawan melakukan pekerjaannya dengan sebaik mungkin walaupun tanpa pengawasan. Misalnya, dengan memberikan pelatihan yang baik dan benar kepada setiap karyawannya sehingga masingmasing karyawan dapat melakukan pekerjaannya dengan baik dengan atau tanpa pengawasan. Bagi peneliti selanjutnya, diharapkan untuk menambah jumlah sampel dan variabel dalam penelitian, karena semakin banyak sampel dan variabel yang digunakan maka data yang dihasilkan akan lebih bervariasi. Selain itu, peneliti berharap agar peneliti selanjutnya dapat mengeksplor variabel independent lain selain lingkungan kerja dan kepuasan kerja untuk mengetahui besar pengaruhnya terhadap loyalitas karyawan. Selain itu, jika peneliti selanjutnya ingin meneliti variabel yang sama untuk digunakan, diharapkan untuk mengkaji ulang variabel kepuasan kerja terhadap loyalitas karyawan agar dapat menghasilkan hasil yang signifikan antar variabel dan juga dapat memberikan hasil yang lebih optimal.

\section{REFERENSI}

Alyani, N., \& Djastuti, I. (2017). Loyalitas karyawan dengan kepuasan kerja sebagai variabel intervening (studi pada PT Kereta Api Indonesia (Persero) Daerah Operasional 4 Semarang). Journal of Management, 6(2), 1-10.

Amin, M., Aldakhil, A. M., Wu, C., Rezaei, S., \& Cobanoglu, C. (2017). The structural relationship between TQM, employee satisfaction and hotel performance. International Journal of Contemporary Hospitality Management, 29(4), 1256-1278. https://doi.org/10.1108/IJCHM-11-2015-0659 
Ashraf, M. A. (2019). The mediating role of work atmosphere in the relationship between supervisor cooperation, career growth and job satisfaction. Journal of Workplace Learning, 31(2), 78-94. https://doi.org/10.1108/JWL-12-2017-0113

Dhir, S., Dutta, T., \& Ghosh, P. (2020). Linking employee loyalty with job satisfaction using PLS-SEM modelling. Personnel Review, 49(8), 1695-1711. https://doi.org/10.1108/PR03-2019-0107

Egenius, S., Triatmanto, B., \& Natsir, M. (2020). The effect of job satisfaction on employee performance through loyalty at credit union (CU) corporation of east kutai district, east kalimantan. International Journal of Multicultural and Multireligious Understanding, 7(10), 480. https://doi.org/10.18415/ijmmu.v7i10.1891

Ellys, E., \& Ie, M. (2020). Pengaruh kepuasan kerja dan budaya organisasi terhadap komitmen organisasi karyawan. Jurnal Manajemen Maranatha, 20(1), 75-84. https://doi.org/10.28932/jmm.v20i1.3026

Ghozali, I. (2016). Aplikasi analisis multivariete dengan program IBM SPSS 23. Badan Penerbit Universitas Diponegoro.

Hair, J. F., Hult, G. T. M., Ringle, C. M., \& Sarstedt, M. (2017). A primer on partial least squares structural equation, odeling (PLS-SEM). (2nd ed.). SAGE Publications, Inc.

Jahanbazi Goujani, A., Shahin, A., Nasr Isfahani, A., \& Safari, A. (2019). Analyzing the influence of job satisfaction on hostage employee loyalty in Isfahan Province Gas Company. Benchmarking, 26(6), 1728-1748. https://doi.org/10.1108/BIJ-04-2018-0093

Jawaad, M., Amir, A., Bashir, A., \& Hasan, T. (2019). Human resource practices and organizational commitment: The mediating role of job satisfaction in emerging economy. $\begin{array}{lllll}\text { Cogent Business \& } & \text { Management, } & 6(1), & 1608668 .\end{array}$ https://doi.org/10.1080/23311975.2019.1608668

Johnson, L. U., Rogers, A., Stewart, R., David, E. M., \& Witt, L. A. (2017). Effects of politics, emotional stability, and LMX on job dedication. Journal of Leadership \& Organizational Studies, 24(1), 121-130. https://doi.org/10.1177/1548051816656004

Khoerunnisa, Y., \& Rahayuningsih, N. (2019). Pengaruh motivasi dan kepuasan kerja terhadap kinerja (studi kasus di Dinas Perhubungan Kabupaten Indramayu). Jurnal Investasi, 5(2), $42-61$.

Khoreva, V., Vaiman, V., \& Van Zalk, M. (2017). Talent management practice effectiveness: investigating employee perspective. Employee Relations, 39(1), 19-33. https://doi.org/10.1108/ER-01-2016-0005

Lee, J. H. J., Ok, C. M., \& Hwang, J. (2016). An emotional labor perspective on the relationship between customer orientation and job satisfaction. International Journal of Hospitality Management, 54, 139-150. https://doi.org/10.1016/j.ijhm.2016.01.008

Loy, A., \& Aageson, T. (2018). Creative economy entrepreneurs: from startup to success: how startups in the creative industries are transforming the global economy. Creative Startups.

Miao, S., Fayzullaev, A. K., \& Dedahanov, A. T. (2020). Management characteristics as determinants of employee creativity: The mediating role of employee job satisfaction. Sustainability (Switzerland), 12(5). https://doi.org/10.3390/su12051948

Okasheh, H., \& AL-Omari, K. (2017). The influence of work environment on job performance: a case study of engineering company in jordan. International Journal of Applied Engineering Research, 12(24), 15544-15550.

Ozimek, A. (2017). Creative economy and culture. Challenges, changes and futures for the creative industries. Information, Communication \& Society, 20(12), 1796-1798. https://doi.org/10.1080/1369118X.2017.1340971

Panda, A., Jain, N. K., \& Nambudiri, R. (2021). Work-family conflict, affective commitment, leadership and job satisfaction: a moderated mediation analysis. International Journal of 
Productivity and Performance Management. https://doi.org/10.1108/IJPPM-01-2020-0040

Rajput, S., Singhal, M., \& Tiwari, S. (2016). Job satisfaction and employee loyalty: a study of academicians. Asian Journal of Management, 7(2), 105. https://doi.org/10.5958/23215763.2016.00015.9

Ramli, A. H. (2019). Work environment, job satisfaction and employee performance in health services. Business and Entrepreneurial Review, 19(1), 29. https://doi.org/10.25105/ber.v19i1.5343

Rohimah, S. (2018). Pengaruh lingkungan kerja terhadap loyalitas karyawan dengan kepuasan kerja sebagai variabel intervening pada PT. Aseli Dagadu Djokdja. Jurnal Ekobis Dewantara, 1(10), 88-100.

Shah, N., Irani, Z., \& Sharif, A. M. (2017). Big data in an HR context: Exploring organizational change readiness, employee attitudes and behaviors. Journal of Business Research, 70, 366-378. https://doi.org/10.1016/j.jbusres.2016.08.010

Shu, E., \& Augustinus, D. C. (2018). Pengaruh pelatihan terhadap kinerja karyawan pada Hotel Santika Premiere Dyandra Medan. Journal of Accounting \& Management Innovation, 2(1), 50-66. https://www.emerald.com/insight/content/doi/10.1108/ER-01-2016-0005/full/html

Supranto, J., \& Limakrisna, N. (2019). Petunjuk praktis penelitian ilmiah untuk menyusun skripsi, tesis, dan disertasi (5th ed.). Mitra Wacana Media.

Suwati, M, M. M., \& Gagah, E. (2016). Influence of motivation work, carrer development and cultural organization on the job atisfaction and implications on the performance of employees (Case on Babinminvetcaddam IV/Diponegoro). Journal Accounting, 2(2), 1-19.

Tannady, H., Erlyana, Y., \& Nurprihatin, F. (2019). Effects of work environment and selfefficacy toward motivation of workers in creative sector in province of Jakarta, Indonesia. Quality - Access to Success, 20(172), 165-168.

Tannady, H., \& Maimury, Y. (2018). Increasing the efficiency and productivity in the production of low voltage switchboard using resource constrained project scheduling. Journal of Industrial Engineering and Management, 11(1), 1. https://doi.org/10.3926/jiem.2228

Tonnisen, U. K., \& Ie, M. (2020). Pengaruh kompensasi dan resiliensi terhadap kepuasan kerja karyawan. Jurnal Muara Ilmu Ekonomi Dan Bisnis, 4(1), 156. https://doi.org/10.24912/jmieb.v4i1.7715

Yu, Q., Yen, D. A., Barnes, B. R., \& Huang, Y. A. (2019). Enhancing firm performance through internal market orientation and employee organizational commitment. International Journal of Human Resource Management, 30(6), 964-987. https://doi.org/10.1080/09585192.2017.1380059 